\title{
ESTUDIO DE LA IGLESIA DE SAN MIGUEL DE MORÓN (SEVILLA). INFLUENCIA DE LOS CAMBIOS DE HUMEDAD EN LA ESTABILIDAD DEL MONUMENTO
}

\author{
(STUDY OF THE CHURCH SAN MIGUEL IN MORÓN, SEVILLA. INFLUENCE OF THE HUMIDITY \\ ALTERATION IN THE STABILITY OF MONUMENT)
}

Jesús Barrios Sevilla*, Antonio Mena Anisi*, Ignacio Valverde Espinosa**, Ángela Barrios Padura*, Jorge
Polo Velasco***

VORSEVI,S.A.

Fecha de recepción: 26-VIII-99

ESPAÑA

\begin{abstract}
RESUMEN
Gran parte de los daños que sufren las fábricas de las edificaciones históricas, tienen su origen en las humedades de capilaridad. Una de las propuestas para eliminarlas es la desviación o modificación del nivel freático. Ello trae consigo la desecación del terreno de apoyo de la cimentación, al pasar de un estado saturado a otro de humedad natural. En aquellos casos en los que los suelos de apoyo de la cimentación estén constituidos por arcillas de alta plasticidad se producirian procesos de retracción, cuya consecuencia podría ser la aparición de asientos diferenciales, que afectarian de forma negativa a la estructura. Para explicar este fenómeno se describe el estudio realizado en la iglesia de San Miguel de Morón de la Frontera (Sevilla).
\end{abstract}

\section{SUMMARY}

Most of the damages that the brick walls of historical buildings show, have the origin in capillary humidity. The way to remove this capillary humidities, is frequently by the deflection of the freatic level. This method causes the dessication of the soil where lays the foundation of the building, and when the soil is constituted of clays of high plasticity, it happens processes of retraction, that causes the differential settling of the foundation, affecting negatively to the structure of the building. To explain this fact, we describe the studies realized in the foundation of the church of San Miguel in Morón, Sevilla.

\section{1.-ANTECEDENTESHISTÓRICOS}

La iglesia parroquial de San Miguel está asentada en el centro de la localidad sevillana de Morón de la Frontera, en una zona de suaves pendientes. La construcción actual se

$\left({ }^{*}\right)$ E. T. S. Arquitectura de Sevilla.

$\left({ }^{* *}\right)$ E. T. S. Arquitectura de Granada.

$(* * *)$ E. U. A. T. de Sevilla. desarrolló entre los años 1503 y 1730. La primera fase se realiza entre 1503-1533, en la que se ejecuta la cimentación, muros y parte de la cubierta. La segunda, corresponde al período 1569 - 1571,;es el más relevante y en él intervienen Martín de Gainza, al que se debe la bóveda de casetones del tramo anterior al crucero y la Capilla de la Antigua y Hernán Ruiz II, que realiza la cúpula y bóvedas pseudovaladas del crucero. Entre 1602 y 1625, Lorenzo de Oviedo ejecuta la Capilla Sacramental y la Sacristía, de acuerdo con el proyecto de Bermudo 
Resta. La última fase corresponde a la primera mitad del s. XVIII, en la que se remodela la Capilla Sacramental $\mathrm{y}$ otros elementos.

La estructura del templo corresponde a la de una planta rectangular, formada por tres naves, de cinco tramos cada una y capillas laterales. La separación entre naves está ejecutada a base de arcos apuntados que apoyan en pilares fasciculados de crucería. Esta estructura da al conjunto un magnífico aspecto, que se ve acrecentado por otros elementos de gran calidad como pueden ser la portada de Diego Antonio Díaz, siguiendo los trazos, al parecer, de Leonardo Figueroa, el retablo Mayor, de Jerónimo Velázquez, la reja de forja que cierra el presbiterio y la torre formada por dos cuerpos con doble remate-cuadrado y circular- y con un cuerpo de campanas inspirado en la Giralda, que presenta en cada lado tres vanos, separados por pilastras toscanas.

\section{2.-DESCRIPCIÓN DE ANOMALÍAS}

En la inspección global realizada al monumento se han detectado las siguientes anomalías:

-En los muros existen importantes concentraciones de humedades por capilaridad, cuyo origen se debe tanto a la proximidad del nivel freático (entre 0,50 y $1 \mathrm{~m}$ de profundidad), como a las filtraciones de aguas residuales procedentes de la red de saneamiento, localizadas en la zona trasera. Aparecen también humedades por filtraciones de cubiertas, grietas, discontinuidades en muros o huecos exteriores, que se manifiestan, preferentemente, en época de lluvias.

-Como consecuencia de estas filtraciones de agua, las piedras presentan una serie de anomalías que se pueden catalogar en los siguientes grupos de alteración:

* Eflorescencias en zócalos y muros.

* Descohesión y disgregación con pérdida de masa.

* En la zona afectada por filtración de aguas procedentes del saneamiento se produce la caída de los frescos y revestimiento de los muros.

-Sobre el suelo de la iglesia se aprecian importantes deformaciones que se traducen en abultamientos de la solería, en especial en el altar mayor, en donde existe una cripta que se encuentra totalmente inundada, funcionando como "aljibe".

-En una de las bóvedas y en el muro lateral derecho aparecen fisuras.

-Uno de los pilares presenta un ligero desplome.

Para el estudio de este monumento, de las anomalías detectadas y de los mecanismos de alteración, se realizaron los siguientes trabajos:

-Apertura de cuatro calicatas hasta alcanzar el terreno de apoyo, para así poder dimensionar la cimentación existente y tomar muestras de los materiales que la componen y del suelo.

-Apertura de nueve calas en muros y pilares para determinar su tipología y tomar muestras de los materiales existentes.

-Levantamiento de mapas de humedad en muros y pilares.

-Estudio geotécnico para caracterizar los diferentes niveles estratigráficos, para lo que se realizaron seis sondeos, con los correspondientes ensayos SPT, toma de muestras inalteradas y situación del nivel freático.

-Análisis y ensayos de las muestras de suelo tomadas en los sondeos: identificación de suelos (límites de Atterberg, granulometría y presencia de carbonatos y sulfatos); ensayos mecánicos (compresión simple y corte directo); deformabilidad (hinchamiento libre, presión de hinchamiento, edometrías e inundación bajo carga).

-Hidrogeología de la zona para conocer el origen y caudales del agua circulante.

-Recopilación de los datos obtenidos e investigación de la relación humedad-alteración de las fábricas y materiales, con propuesta de soluciones.

De este amplio estudio se han seleccionado los datos de interés para los objetivos marcados en el mismo y que era la posible desviación del agua circulante en el entorno de esta iglesia para evitar, de este modo, la ascensión de humedades por capilaridad.

\section{3.- DEFINICIÓN Y DIMENSIONAMIENTO DE ELEMENTOSCONSTRUCTIVOS}

De la serie de ensayos y determinaciones realizadas para comprobar las características, composición y dimensionamiento de diferentes unidades y elementos constructivos, se obtuvieron una serie de datos que ponen de relieve los siguientes aspectos:

* Los muros tienen un espesor y composición variable según las zonas:

-La fachada principal es de doble hoja con adosados y su composición desde el exterior es: sillería de piedra arenisca, cogida con mortero de cal, con un espesor de $85 \mathrm{~cm}$; núcleo de argamasa con trozos de ladrillo y roca, de $70 \mathrm{~cm}$ y sillería de piedra arenisca de $80 \mathrm{~cm}$, sobre la 
que se adosa un conjunto formado por morteró de cal con restos cerámicos y trozos de roca. El conjunto tiene un espesor total de $255 \mathrm{~cm}$.

-En el muro frontal derecho la composición del primer tramo corresponde también a una tipología de doble hoja con adosado, cuya disposición de fuera-dentro es: sillería de arenisca, de $50 \mathrm{~cm}$; núcleo de argamasa con restos cerámicos y trozos de piedra arenisca, de $170 \mathrm{~cm}$ y sillería de piedra arenisca, de $31 \mathrm{~cm}$, lo que da un espesor al conjunto de $251 \mathrm{~cm}$. Además lleva incorporado un adosado de piedra arenisca y trozos de ladrillo, tomados con mortero de cal.

En el segundo tramo, a nivel del crucero, el muro está formado por mampostería de piedra caliza, tomada con mortero de cal de $60 \mathrm{~cm}$; a continuación una mampostería de piedras areniscas y calizas, tomadas con mortero de cal de $64 \mathrm{~cm}$ y, como remate, aparece un emparchado de ladrillo hueco simple tomado con mortero de cemento y enfoscado, de $12 \mathrm{~cm}$ de grueso, de reciente construcción. El conjunto tiene un espesor total de $136 \mathrm{~cm}$.

-En la zona trasera del muro frontal izquierdo, la composición corresponde a una mampostería de piedras areniscas y calizas tomadas con mortero de cal, de $125 \mathrm{~cm}$.

-El muro correspondiente a la fachada trasera está formado por mampostería de piedra arenisca de $78 \mathrm{~cm}$, que se ha revestido con una cítara de ladrillo macizo, dejando una cámara de aire de $50 \mathrm{~cm}$.

* Los pilares están formados por una envolvente de sillares de piedra arenisca, formando una corona de unos $35 \mathrm{~cm}$ y un núcleo de $105 \mathrm{~cm}$ de mampostería de piedra arenisca y mortero de cal.

* Las muestras de piedra arenisca tomadas de los muros fueron sometidas a diferentes ensayos, obteniéndose los siguientes datos:
-La porosidad oscila entre el 18,5 y $22,1 \%$.

-La resistencia a compresión de la piedra arenisca en estado seco, entre 53,5 y $69,7 \mathrm{~kg} / \mathrm{cm}^{2}$.

-La resistencia a compresión de la piedra arenisca saturada de agua, entre 36,7 y $52,7 \mathrm{~kg} / \mathrm{cm}^{2}$.

Se trata, por tanto, de una arenisca de baja resistencia y alta porosidad, que, cuando está saturada de agua, reduce su resistencia a compresión un 38\%.

* Los morteros de agarre tienen una alta proporción de conglomerante, con dosificaciones en volumen comprendidos entre 1 y 2,5 partes de cal por una de arena silícea y una porosidad media-alta (entre 19 y $26 \%$ ).

Tanto las muestras de piedra como los morteros, presentan fracciones apreciables de compuestos potencialmente agresivos como sulfatos, nitratos, nitritos, amoniaco y cloruros.

\section{4.- ESTUDIO DE LA CIMENTACIÓN Y DEL TERRENODE APOYO}

Para comprobar la cimentación existente y el terreno sobre el que apoya, se han realizado seis sondeos y cuatro calicatas. De los datos obtenidos -y del informe correspondiente- se extrae el siguiente resumen.

\section{1.- Cimentación}

Es heterogénea, tanto por lo que se refiere a dimensionamiento, como a composición y plano de apoyo. Así, en la fachada principal y adyacentes, el muro, conformado por sillares de piedra, continúa por debajo de la cota de acerado, entre 42 y $52 \mathrm{~cm}$, apoyando sobre una zanja corrida de argamasa (hormigón calizo), con un

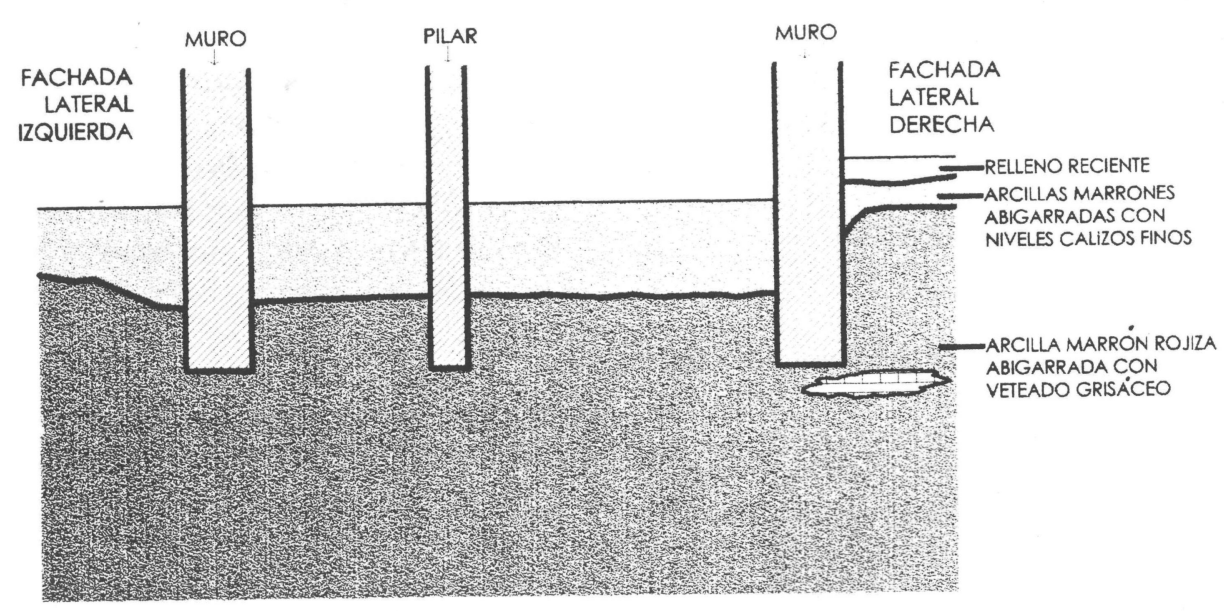

Figura 1 
sobreancho, en relación al muro, entre 50 y $64 \mathrm{~cm}$ en cada cara y una profundidad variable, entre 220 y $290 \mathrm{~cm}$.

En la fachada trasera y zonas aledañas, el muro está realizado a base de una mampostería de piedra arenisca con verdugadas de ladrillo macizo, tomadas con mortero de cal, que profundiza $42 \mathrm{~cm}$, desde la cota del acerado, continuando con fábrica de ladrillos macizos tomados con mortero de cal, con un sobreancho de $35 \mathrm{~cm}$ en cada cara y una profundidad que oscila entre 220 y $280 \mathrm{~cm}$.

En la torre los muros profundizan $80 \mathrm{~cm}$ desde la cota del acerado, apoyando en una argamasa constituida por trozos de piedra y ladrillos englobados en mortero de cal. El sobreancho, en relación con el muro, es de $175 \mathrm{~cm}$, en la cara exterior. El plano de apoyo se sitúa a $290 \mathrm{~cm}$ desde la cota de acerado.

Los pilares tienen una cimentación realizada a base de sillares de piedra arenisca y calizas micríticas, tomados con mortero de cal. La profundidad de la misma es de $290 \mathrm{~cm}$.

En todas las cimentaciones abiertas no se observan alteraciones de ningún tipo.

\section{2.- Terreno de apoyo. Características geotécnicas}

\subsection{1.- Niveles estratigráficos diferenciados. Caracterización geomecánica de los mismos}

A través de los ensayos geotécnicos realizados, se han podido diferenciar los siguientes niveles estratigráficos, comenzando por el más superficial hasta llegar al más profundo reconocido.

Nivel 1: Rellenos superficiales, solerías y/o cimentaciones de la iglesia

Este nivel tiene un espesor que oscila entre 0,50 y $1,50 \mathrm{~m}$ en la fachada principal y laterales y de 3 a $5,30 \mathrm{~m}$ en la fachada trasera. Se incluye en él a las solerías, soleras y pavimentos superficiales, bajo los cuales aparecen rellenos arcillosos propiamente dichos, mezclados con restos cerámicos, trozos de roca, argamasa, etc.

Al tratarse de un recubrimiento artificial, heterogéneo, los valores de consistencia obtenidos son bajos, oscilando entre medios y blandos.

En este nivel no apoya ninguna de las cimentaciones existentes.

Nivel 2: Sustrato Triásico: arcillas versicolores verdosas o rojizas con abundante material granular, cantos calizos, yeso abundante, etc.

Según los valores obtenidos en los sondeos realizados, el

techo de este estrato aparece bajo el anterior entre $0,50 \mathrm{y}$ 3,00 m, alcanzándose puntualmente los 5,30 en la fachada trasera. El espesor, según los datos de los sondeos, oscila entre 8 y $10 \mathrm{~m}$.

En este nivel es donde apoyan todas las cimentaciones de este complejo monumental. Corresponde al sustrato Triásico, típico de la zona, integrado por suelos arcillolimosos de media-alta plasticidad, de coloraciones abigarradas o versicolores, rojizas, verdosas, grisáceas. Incluye abundante material granular calizo o yesífero y algunos cantos o bloques rocosos de similar naturaleza, todo ello con una estructura muy caótica. El espesor de este estrato es de varios centenares de metros, según los mapas geológicos.

Los ensayos identificativos realizados sobre este nivel evidencian los siguientes parámetros:

- Límites de Atterberg

Límite líquido:

Límite plástico:

Índice de plasticidad:

entre 50,0 y $67,4 \%$

entre 29,4 y $40,4 \%$

entre 15,1 y $33,7 \%$

- \% pasa Tamiz 4 ASTM:

entre 99 y $100 \%$

- \% pasa Tamiz 200 ASTM:

entre 86 y $99 \%$

En base a esta información, correspondiente a los ensayos de identificación, puede definirse este suelo como $\mathrm{CH}-\mathrm{MH}$.

La humedad natural de las muestras oscila entre el 31,4 y $40,8 \%$.

A partir de la humedad natural y de los límites de Atterberg, pueden deducirse los valores del índice de fluidez (IF) y del índice de desecación (ID):

- IF: oscila entre $-0,52$ y 0,23

- ID: oscila entre 0,80 y 1,12

Dado el carácter arcilloso y potencialmente expansivo que presentan estos niveles, se han realizado ensayos por métodos directos e indirectos, siguiendo los criterios expresados por diferentes autores, de entre los que cabe destacar Chen (1965), Vijayvergiya y Ghazzaly (1973), Lambe (1960), Jiménez Salas (1980), Delgado Trujillo (1986).

De los ensayos y estudios realizados se han obtenido los parámetros necesarios para clasificar estos materiales según los diferentes criterios y autores:

-Clasificación:

-Presión de hichamiento: expansividad alta a muy alta entre $1,5 \mathrm{y}>2 \mathrm{~kg} / \mathrm{cm}^{2}$ 
-Hinchamiento libre:

entre 4,5 y $7,1 \%$

De los ensayos de corte directo, consolidados y drenados, se han obtenido los siguientes parámetros:

Cohesión:

entre 0,21 y $0,33 \mathrm{~kg} / \mathrm{cm}^{2}$

Ángulo de rozamiento:

entre $25,6^{\circ}$ y $27,9^{\circ}$

De lo anteriormente expuesto puede establecerse la siguiente carga admisible.

A corto plazo $\mathrm{q}_{\mathrm{adm}}=2,50 \mathrm{~kg} / \mathrm{cm}^{2}$

A largo plazo (situación actual) los valores de carga admisibles son más elevados al estar el suelo consolidado y drenado, con lo cual puede alcanzarse un valor de $\mathrm{q}_{\mathrm{adm}}=5,00 \mathrm{~kg} / \mathrm{cm}^{2}$.

El nivel freático aparece a una profundidad comprendida entre 1,60 y 2,00 m, desde la cota del acerado. Los análisis químicos realizados a las muestras de agua tomadas del subsuelo, ponen de manifiesto una alta concentración de sulfatos y cloruros. En la zona trasera el agua aparece a $-0,70 \mathrm{~m}$, al proceder de la rotura de la red de saneamiento próxima. Los resultados obtenidos en el análisis químico de este agua indican una elevada proporción de cloruros, sulfatos, nitratos, nitritos, amoniaco y materia orgánica.

\section{5.-HUMEDADES EN LOS MUROS Y PILARES}

La observación de los muros, pilares y solerías de esta iglesia, indican la existencia de humedades de capilaridad, que los afectan de forma importante, como lo demuestran las alteraciones que presentan las piedras y los morteros de las juntas y llagas. Para el estudio de este agente de alteración y de su mecanismo de acción se han realizado dos trabajos concurrentes. De un lado conocer la hidrología de la zona y, de otro, medir la humedad de los diferentes elementos afectados.

\section{1.- Hidrogeología}

La iglesia de San Miguel está enclavada en una zona deprimida en relación con dos resaltes relativamente importantes para la topografía suave de la zona. Estas elevaciones se encuentran constituidas por calizas, brechas calcáreas, carniolas, jurásicas y triásicas, coluviales y derrubios cuaternarios, que apoyan sobre materiales arcillosos triásicos relativamente impermeables. Por lo tanto, pueden actuar como acuíferos libres, con las limitaciones hidrogeológicas propias de la zona. Dadas sus reducidas dimensiones, el aporte de caudal no es muy importante, como lo demuestra el hecho de que en época de sequía, la capacidad de los pozos del entorno se reduce considerablemente.

El gradiente hidráulico, por otra parte, está orientado hacia el Oeste, aprovechando la topografía suave existente. En este caso el acuífero presenta características de aporte libre, cuyo nivel piezométrico fluctúa dependiendo de las precipitaciones y de su explotación antrópica, estando enmarcado entre el sustrato triásico arcilloso y la superficie, constituida por limos arcillosos, procedentes de la propia alteración de los materiales triásicos y de la cobertera cuaternaria existente. Esto daría un acuífero de pequeña entidad.

A estos materiales hay que añadir los rellenos antrópicos, que al ser una zona donde el asentamiento humano es muy antiguo, puede alcanzar espesores de hasta cinco metros.

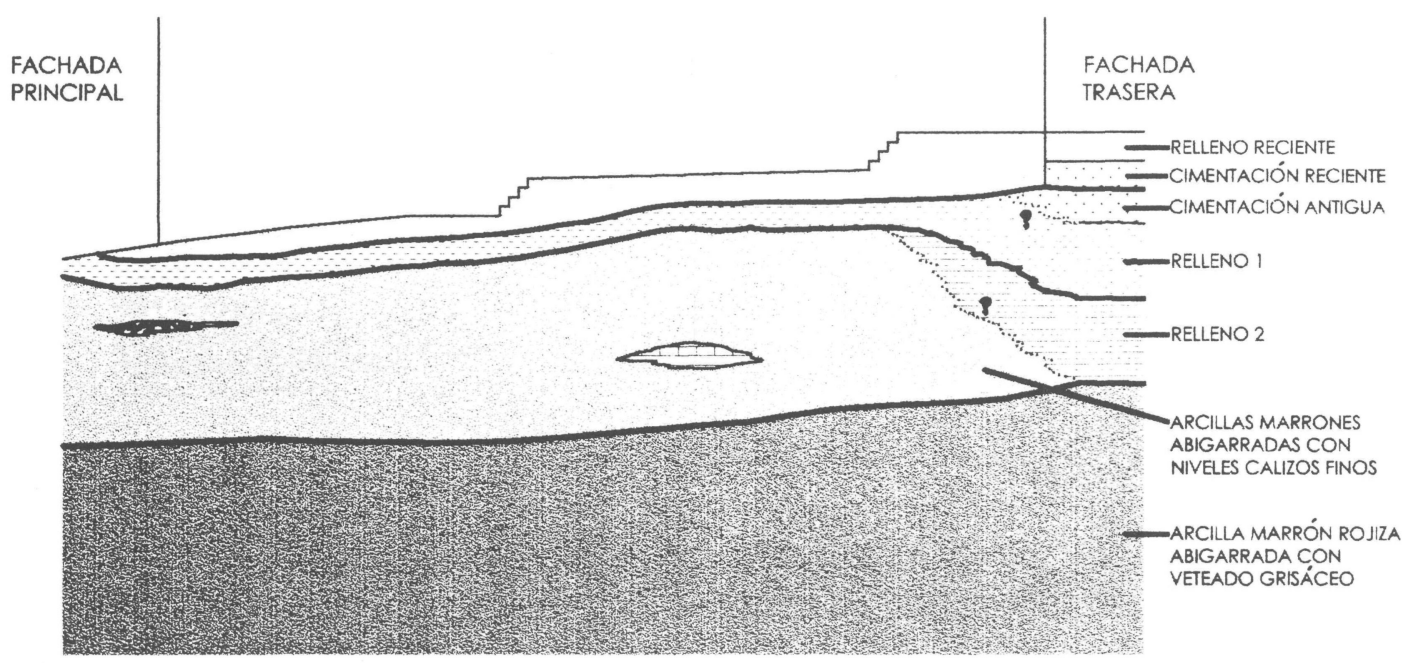

Figura 2 
Por todo cuanto antecede, puede deducirse que las importantes humedades que presentan los pilares, solería y muros de la iglesia de San Miguel, son el resultado de la actuación conjunta de dos fenómenos. El primero, sería la existencia de un flujo de "agua natural", que discurre por la cobertera Cuaternaria y los rellenos existentes, por lo que podría considerarse como un acuífero libre de poca entidad con las características específicas en estos casos: la dependencia de aportes continuos para mantener el caudal relativamente estable y la alta transmisividad debida a la topografía de la zona y a la naturaleza de los materiales.

El segundo fenómeno sería el de aportaciones artificiales de agua al paquete de materiales más permeable, que, en este caso, se genera por la existencia de fugas importantes en la canalización próxima a la iglesia de San Miguel, en donde el espesor de los rellenos es mayor. Esta acción es circunstancial, pudiéndose eliminar con el arreglo del saneamiento de la calle adyacente.

\section{2.- Índices de humedad}

Para la determinación del contenido de humedad en muros y pilares se ha empleado la técnica del higrómetro de contacto, técnica que determina el índice de humedad del material en función de la conductividad que presenta el elemento ensayado. Estos índices se pueden correlacionar con el porcentaje de humedad, a través de su determinación en una serie de muestras de las que se conoce su índice de humedad.
Utilizando esta metodología, se han identificado las zonas con mayor grado de humedad del elemento estudiado y el gradiente correspondiente desde la base hasta los $2 \mathrm{~m}$ de altura.

De las medidas y gráficos obtenidos se deduce la siguiente distribución de humedades:

-En la fachada principal la zona del zócalo tiene una humedad comprendida entre el 5 y $10 \%$, hasta una altura que oscila entre los 50 y $180 \mathrm{~cm}$. A partir de esa cota los valores de humedad son inferiores al $3 \%$. La zona en la que la humedad de capilaridad alcanza mayor altura es la frontal derecha.

-El muro derecho tiene dos zonas amplias en las que la humedad alcanza valores comprendidos entre el 15 y $20 \%$, a una cota de más de $2 \mathrm{~m}$ de altura. En el resto, la humedad de los primeros $50-100 \mathrm{~cm}$ del muro oscila entre 5 y $10 \%$ y a partir de ese nivel son inferiores al $5 \%$, descendiendo de forma gradual con la altura del muro.

-En el muro frontal izquierdo, que linda con la torre, se distinguen dos zonas. La primera, que es la comprendida entre la fachada y la puerta lateral, en la que hasta una altura de $150-200 \mathrm{~cm}$ la humedad oscila entre el 5 y $10 \%$, a partir de esa cota desciende por debajo del $5 \%$, de forma gradual, conforme se asciende. La otra corresponde al tramo situado entre la puerta y la fachada trasera, en la que la humedad es superior al $15 \%$ en toda la altura medida, que son $200 \mathrm{~cm}$. Esto significa que la afluencia de agua
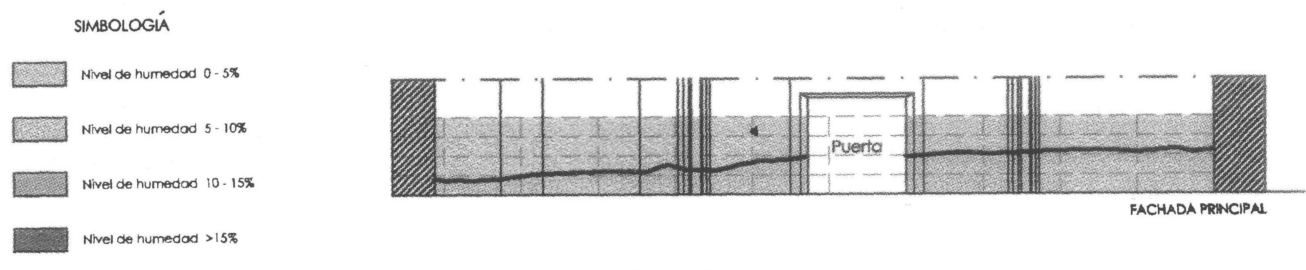

Figura 3
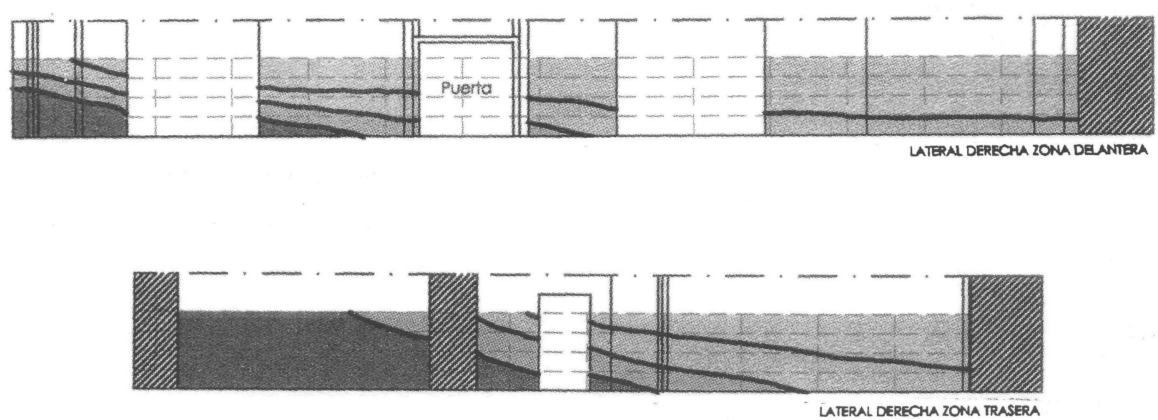

Figura 4 

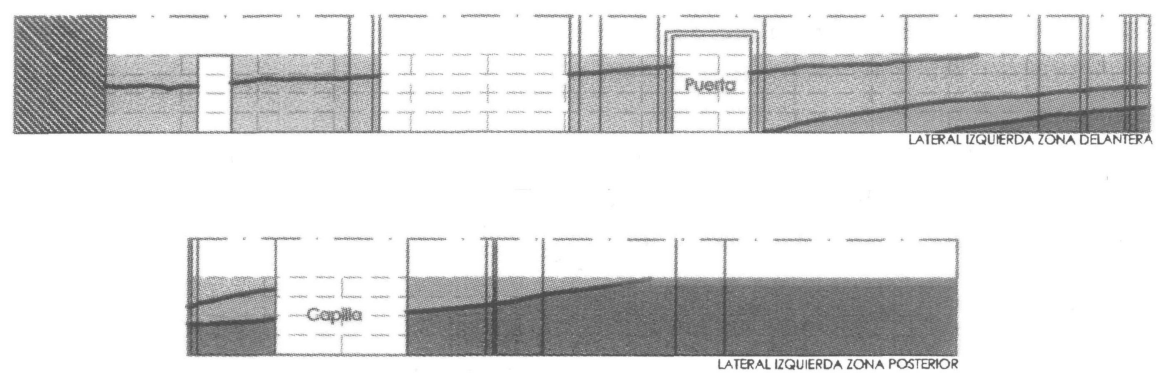

Figura 5

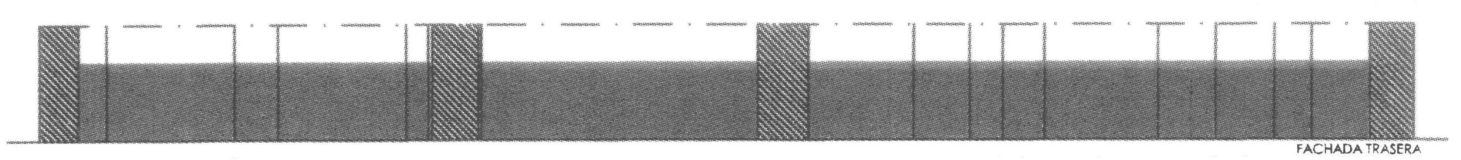

Figura 6

procedente de la rotura de la red de saneamiento de la calle perpendicular a la fachada trasera, está afectando de forma considerable a este muro.

-En la fachada trasera la humedad del muro está comprendida entre el 15 y $20 \%$, alcanzando una altura de seis metros. La causa es el agua procedente de la rotura de la red de saneamiento de la calle.

Con estos datos parece confirmarse que la iglesia está dividida en dos mitades, a efectos de humedades de capilaridad. La delantera está influenciada por el agua freática, con valores entre el 5 y $10 \%$ y altura variable, entre 50 y $150 \mathrm{~cm}$, a partir de las cuales va disminuyendo de forma gradual desde el 5 al 1\%. La segunda, que corresponde a la mitad posterior, está influenciada de forma decisiva por la rotura de la red de saneamiento, con valores de humedad superiores al $15 \%$ y ascensión capilar de hasta seis metros.

Esta distribución de humedades y su distinto origen y composición condiciona las alteraciones que presentan los sillares de piedra. En la primera zona las anomalías creadas por el agua freática se concretan en una desagregación que afecta principalmente a su textura superficial. En la segunda, la humedad procede de aguas residuales cargadas de materia orgánica, nitratos, nitritos y amoniaco, que provocan la degradación y destrucción tanto de la piedra como de los revestimientos de estuco y las pinturas.

\section{6.-PROPUESTA DE SOLUCIONES}

Por lo anteriormente expuesto, se deduce que las anomalías que presentan los muros y pilares de la iglesia de San (c) Consejo Superior de Investigaciones Científicas Licencia Creative Commons 3.0 España (by-nc)
Miguel se deben a la existencia de humedades de capilaridad originadas por la existencia de agua fréatica, fundamentalmente $y$, de forma puntual, por la rotura del saneamiento que bordea el cerramiento posterior. En este trabajo se considera, únicamente, la acción de la primera, que es la que ha producido las alteraciones descritas, ya que la segunda, procedente del saneamiento, se elimina con el arreglo de las conducciones. La tipología de las fábricas descritas en el apartado 3 favorece este fenómeno, así como los materiales constituyentes, ya que tanto los sillares de piedra como los morteros tienen características físicas y estructurales que facilitan los fenómenos de succión y capilaridad. Asimismo, cabe recordar que estas areniscas disminuyen un $38 \%$ su resistencia a compresión cuando están saturadas de agua. Es fundamental, por tanto, cortar la ascensión del agua para lo que, entre otras soluciones, puede optarse por la desviación del caudal circulatorio. En el caso de tomar esta decisión es necesario conocer el efecto que puede producirse con la desecación de suelos que poseen altos índices de plasticidad, expansividad y deformaciones volumétricas.

Se trata, por tanto, de efectuar un análisis de comportamiento de la cimentación y estructura de la iglesia en la hipótesis de que los tratamientos de contención y derivación de las aguas fréaticas reduzcan el contenido de humedad del subsuelo, desde el actual estado de saturación a otro en el que el contenido de humedad natural es muy inferior al existente, lo que puede llevar aparejado un asiento adicional por desecación y retracción de las arcillas.

Resulta complejo estimar el asiento por desecación, pues es difícil evaluar las variaciones volumétricas que puedan tener lugar, derivadas de la pérdida de agua en la red porosa o capilar y en la propia estructura mineralógica de la http://informesdelaconstruccion.revistas.csic.es 
arcilla; el descenso del nivel freático conduce a una disminución de volumen por desaparición gradual de la presión intersticial y aumento de la presión en la estructura de la arcilla, es decir, se producirá una contracción. Por tal motivo, se han efectuado algunas simplificaciones para adoptar un modelo de cálculo que, aunque pueda no coincidir con el proceso real previsible, permita establecer un orden de magnitud del fenómeno. En concreto, se ha seguido un sistema análogo al de evaluación del hinchamiento unitario bajo carga, considerando que, en este caso, el proceso se realiza a la inversa.

La determinación del hinchamiento/retracción se realiza a partir del método simplificado del Profesor Delgado Trujillo, a partir « los ensayos de inundación bajo carga.
El hinchamiento o retracción unitaria, viene determinado por la expresión:

$$
\mathrm{R}=\Sigma(\mathrm{E} \cdot \mathrm{z})
$$

siendo: $\mathrm{z}=$ Espesor de cada capa en que se divide el estrato

$\mathrm{E}=$ Hinchamiento o retracción unitaria del punto central de cada capa.

El hinchamiento o retracción de cada capa se asimila al de su punto central. Al producirse desecación del terreno, la retracción unitaria, E, viene determinada por la diferencia entre la curva de humedad natural y la curva de inundación bajo carga que, en este caso, se considera de retracción a la inversa.

TABLA 1

\begin{tabular}{|c|c|c|c|c|c|c|}
\hline \multirow{6}{*}{ MUESTRAS DEL } & CAPA & $\sigma\left(\mathrm{kp} / \mathrm{cm}^{2}\right)$ & $\begin{array}{l}\mathrm{z} \text { espesor } \\
\text { (m) }\end{array}$ & $\mathrm{E}(\%)$ & $E \cdot z$ & $\begin{array}{c}\Sigma(\mathrm{E} \cdot \mathrm{z}) \\
(\mathrm{cm})\end{array}$ \\
\hline & $0,00-1,00$ & 0,095 & 1,0 & 5,7 & 5,7 & 5,7 \\
\hline & $1,00-2,00$ & 0,28 & 1,0 & 3,5 & 3,5 & 3,5 \\
\hline & $2,00-3,00$ & 0,48 & 1,0 & 2,5 & 2,5 & 2,5 \\
\hline & $3,00-4,00$ & 0,66 & 1,0 & 2,0 & 2,0 & 2,0 \\
\hline & $4,00-5,00$ & 0,85 & 1,0 & 1,8 & 1,2 & 1,2 \\
\hline
\end{tabular}

ENSAYO DE INUNDACIÓN BAJO CARGA

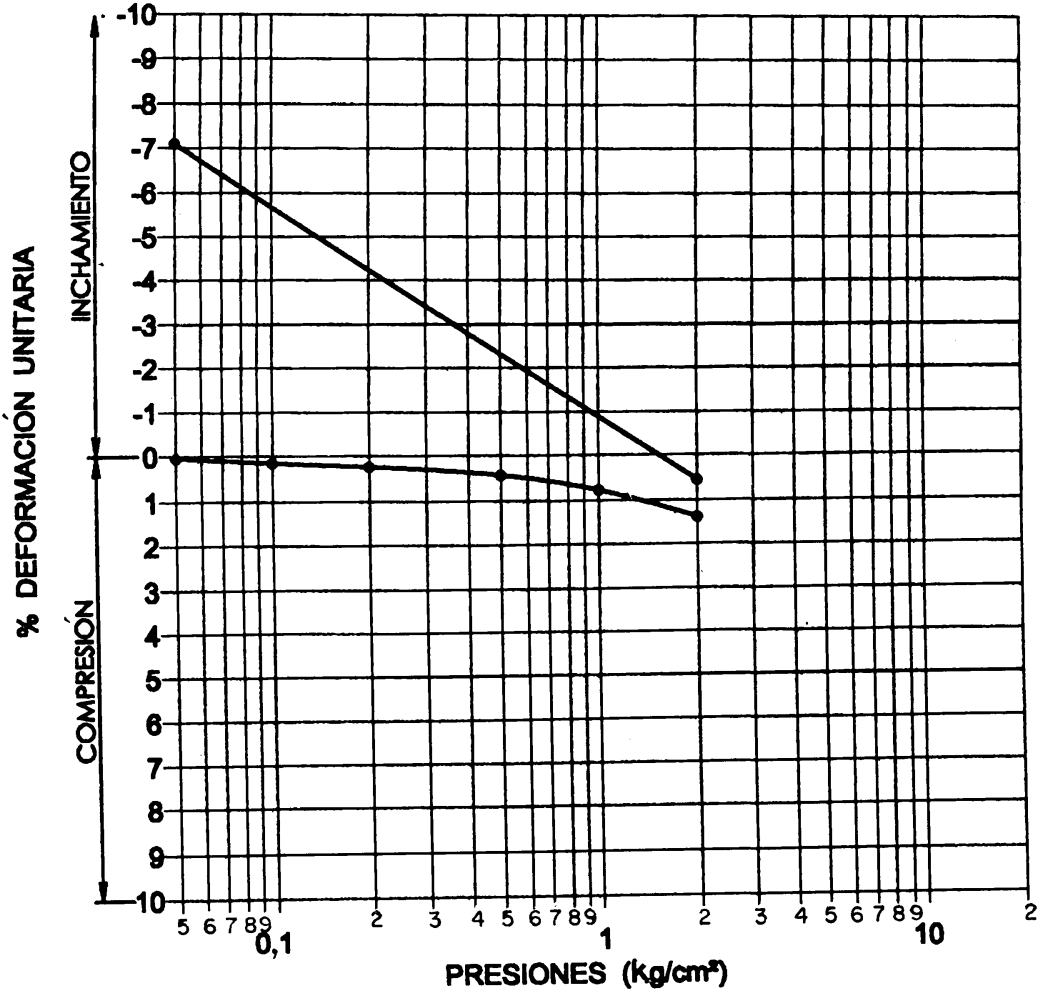


La presión bajo la que se produce hinchamiento/retracción es la presión total que actúa sobre el punto medio del estrato: presión debida al peso de las tierras superiores, más presión transmitida por la cimentación.

Para el cálculo del hinchamiento/retracción de la superficie del terreno libre consideramos 5 capas de 1,0 m cada una, que totalizan $5,0 \mathrm{~m}$ de profundidad máxima, que es la que se estima que puede ser afectada por los cambios de humedad. Por debajo de esa cota los cambios de volumen son inapreciables, de forma genérica.

Se han tomado los datos correspondientes a las muestras de terreno que sirven de apoyo a la cimentación de este monumento que, como ya se ha indicado, se trata de arcillas de alta expansividad (Tabla 1).

Este valor de $14,9 \mathrm{~cm}$ de descenso corresponde al terreno natural en ausencia de cimentaciones. Para una cimentación implantada a 3,0 m-como es el caso-se registra una deformación unitaria de hinchamiento/ retracción del $0,85 \%$, lo que supone una retracción final de $1,7 \mathrm{~cm}$ en la hipótesis contemplada.
Otro fenómeno que puede darse con la desecación es la presencia de posibles hinchamientos. En la actual situación las arcillas están saturadas, no existiendo cambios humectación - desecación - humectación, que son los que generan los cambios de volumen. Si estos suelos se desecan se corre el riesgo de iniciar el proceso anteriormente descrito, añadiéndose un factor negativo importante para la estabilidad de las fábricas.

Puede concluirse, por tanto, que, en caso de optar por la solución de eliminar la afluencia de agua freática, podrían tener lugar disminuciones de volumen considerables en el suelo portante, con el consiguiente asiento, posiblemente diferencial, que afectaría de forma negativa a los muros, pilares y cubierta que conforman la estructura de esta iglesia.

Por ello, entendemos que la propuesta de actuación debe dirigirse en el sentido de crear barreras que impidan la ascensión capilar, evitándose cualquier modificación del grado de humedad de las arcillas que puedan llegar a producir deformaciones adicionales de los suelos, ya sean retracciones, asientos o hinchamientos.

\title{
Publicación del Instituto Eduardo Torroja - CSIC
}

\author{
Número monográfico de INFORMES
}

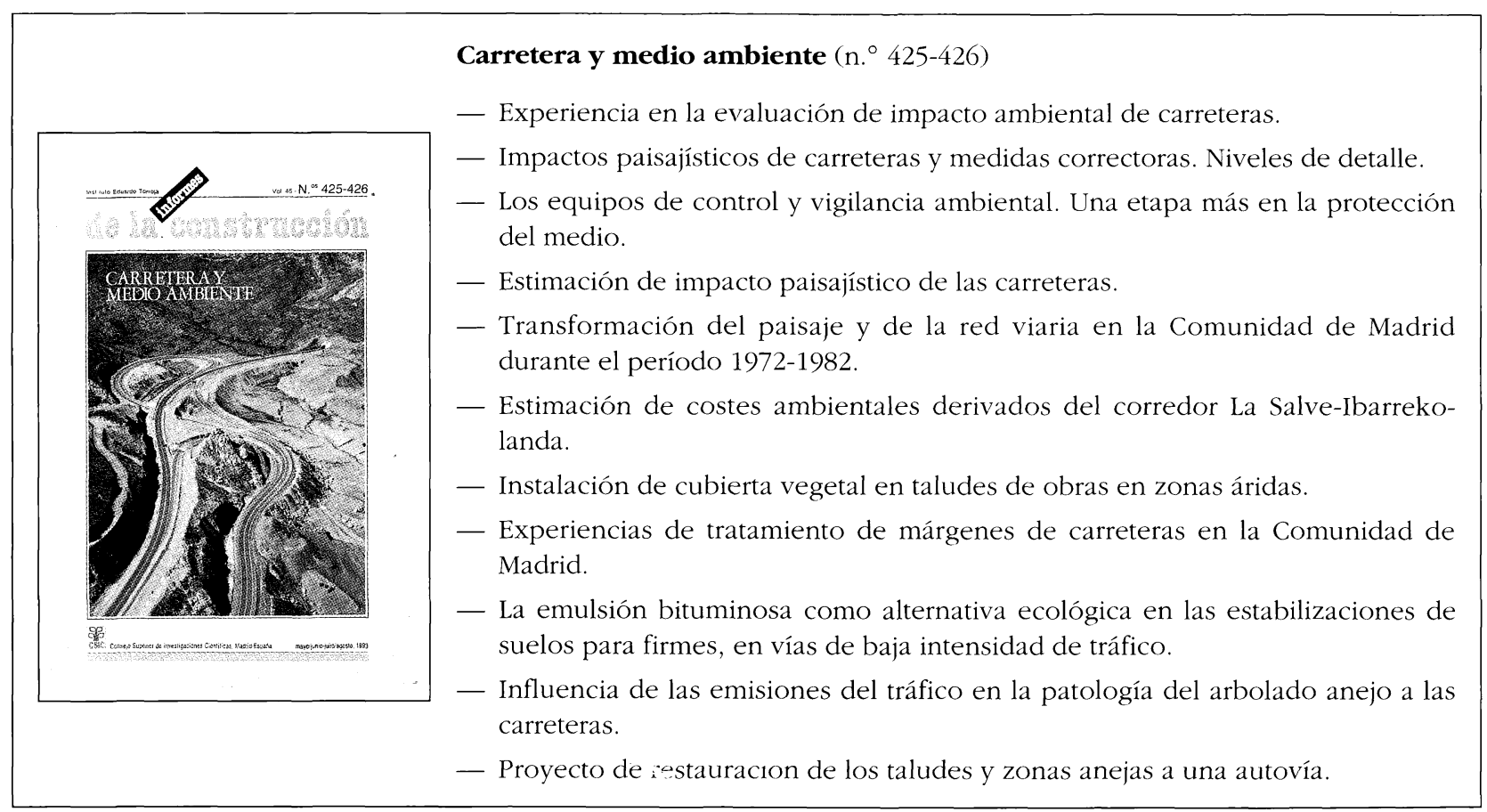

